ARTICLE

httpst//doi.org/10.1038/s414.67-020-14859-z

\title{
Tin-graphene tubes as anodes for lithium-ion batteries with high volumetric and gravimetric energy densities
}

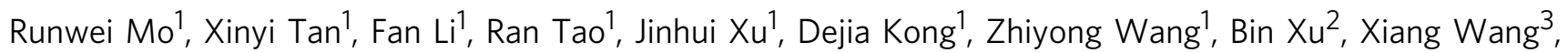
Chongmin Wang $\mathbb{B}^{3}{ }^{3}$, Jinlai $\mathrm{Li}^{4}$, Yiting Peng ${ }^{5 凶} \&$ Yunfeng Lu四

Limited by the size of microelectronics, as well as the space of electrical vehicles, there are tremendous demands for lithium-ion batteries with high volumetric energy densities. Current lithium-ion batteries, however, adopt graphite-based anodes with low tap density and gravimetric capacity, resulting in poor volumetric performance metric. Here, by encapsulating nanoparticles of metallic tin in mechanically robust graphene tubes, we show tin anodes with high volumetric and gravimetric capacities, high rate performance, and long cycling life. Pairing with a commercial cathode material $\mathrm{LiNi}_{0.6} \mathrm{Mn}_{0.2} \mathrm{Co}_{0.2} \mathrm{O}_{2}$, full cells exhibit a gravimetric and volumetric energy density of $590 \mathrm{Wh} \mathrm{Kg}^{-1}$ and $1,252 \mathrm{Wh} \mathrm{L}^{-1}$, respectively, the latter of which doubles that of the cell based on graphite anodes. This work provides an effective route towards lithium-ion batteries with high energy density for a broad range of applications.

\footnotetext{
${ }^{1}$ Chemical and Biomolecular Engineering, University of California, Los Angeles, CA 90095, USA. ${ }^{2}$ State Key Laboratory of Supramolecular Structure and Materials, Jilin University, 130012 Changchun, China. ${ }^{3}$ Environmental Molecular Sciences Laboratory, Pacific Northwest National Laboratory, Richland, WA 99352, USA. ${ }^{4}$ ENN Group, Langfang, 065001 Hebei, China. ${ }^{5}$ Shanghai Key Laboratory of Materials Protection and Advanced Materials in Electric Power,

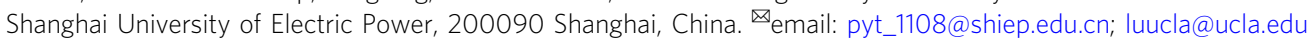


T here are increasing demands for lithium-ion batteries (LIBs) with high gravimetric energy; meanwhile, due to the limited space that are available to accommodate the batteries in microelectronics and electric vehicles, developing LIBs with high volumetric energy density is also emerging as a particularly important theme $\mathrm{e}^{1-5}$. The current LIBs generally adapt graphite as the anode material and lithium-nickel-manganesecobalt oxides (NMC) as the cathode materials. Graphite has a theoretical gravimetric capacity of $372 \mathrm{~mA} \mathrm{~h} \mathrm{~g}^{-1}$ (based unlithiated graphite), crystal density of $2.266 \mathrm{~g} \mathrm{~cm}^{-3}$, and volumetric capacity of $841 \mathrm{~mA} \mathrm{~h} \mathrm{~cm}^{-3}$ (based on un-lithiated graphite) ${ }^{6}$ or $719 \mathrm{~mA} \mathrm{~h} \mathrm{~cm}^{-3}$ (based on full-lithiation graphite) $)^{7}$. Whereas the commercially used graphite generally has a low tap density (e.g., $1.1 \mathrm{~g} \mathrm{~cm}^{-3}$ ), which occupies a significant portion of a battery volume $^{8}$. For example, when paired with commercial cathode materials (e.g., NMC111, NMC523, NMC622, and NCM811), the graphite coatings could account for $55-60 \%$ of the volume of a cell, including the anode and cathode coatings, current collector, and separator ${ }^{9-11}$. Exploring novel anode materials that can reduce the volume of the anode coatings occupied, in this context, is of paramount importance towards LIBs with significantly improved volumetric energy density.

Among the vast library of anode materials, metals and metal oxides generally exhibit significantly higher volumetric capacities than the carbonaceous materials owning to their high gravimetric capacity and tap density ${ }^{12-15}$. For example, tin (Sn) has a theoretical volumetric capacity of $7316 \mathrm{~mA} \mathrm{~h} \mathrm{~cm}^{-3}$ (based on unlithiated $\mathrm{Sn})^{16-18}$ or $2111 \mathrm{~mA} \mathrm{~h} \mathrm{~cm}^{-3}$ (based on full-lithiation $\mathrm{Sn}$ ), respectively, which are significantly higher than those of graphite $\left(841 \mathrm{~mA} \mathrm{~h} \mathrm{~cm}^{-3}\right.$ and $719 \mathrm{mAh} \mathrm{cm}^{-3}$, respectively) ${ }^{7,16-18}$. In addition, $\mathrm{Sn}$ is a low-cost material with a low working potential $\left(<0.5 \mathrm{~V}\right.$ versus $\left.\mathrm{Li}^{2} \mathrm{Li}^{+}\right)$, making it a highly promising anode candidate with both high volumetric and gravimetric energy density.
In fact, $\mathrm{Sn}$ was commercially used as the anodes for Nexelion made by Sony ${ }^{19,20}$. Nonetheless, Sn exhibits large-volume change during the lithiation and delithiation, which disrupts the electrode structure and electronic conductive networks and results in poor cycling life $^{19,20}$. To address these issues, various $\mathrm{Sn}, \mathrm{Sn}$ alloys ${ }^{21-25}$, and Snbased composites ${ }^{26-35}$ with designed structures (e.g., nanowires, nanosheets, and porous structures $)^{36-40}$ and compositions have been explored, whereas making $S n$ anodes with high energy density and long cycling life remains challenging.

We show a design of high-performance Sn anodes, which were made by confining Sn nanoparticles within the frameworks of graphene tubes. As illustrated in the Fig. 1a, using magnesium oxide $(\mathrm{MgO})$ as the template and catalyst, we first grew nitrogendoped graphene around $\mathrm{MgO}$ nanowires by chemical vapor deposition (CVD) using acetonitrile as the precursor. As-formed graphene-coated nanowires were then coated with a thin layer of $\mathrm{MgO}$, on which graphene was grown using methane as the precursor (Supplementary Fig. 1). Removal of the templates leads to the formation of double-graphene-tubes (DGT), which consists of an inner hydrophilic graphene tube (nitrogen-doped) and an outer hydrophobic graphene tube (un-doped). Dispersing the DGT in a $\mathrm{K}_{2} \mathrm{SnO}_{3}$ solution allows the aqueous precursor to infiltrate into the hydrophilic tubes, as well as growth of $\mathrm{SnO}_{2}$ nanoparticles within the inner tubes in a subsequent hydrothermal reaction. Finally, reducing the $\mathrm{SnO}_{2}$ nanoparticles leads to the formation of Sn nanoparticles encapsulated within the double-graphene-tubes, denoted as Sn/DGT.

As depictured in the Fig. 1b, by confining the Sn nanoparticles within the electronically conductive and mechanically robust DGT, the structural integrity of the electrodes, as well as the electronconduction networks among the nanoparticles, could be well preserved, despite their large-volume change during the lithiation and delithiation. In addition, the small size of the Sn nanoparticles

a

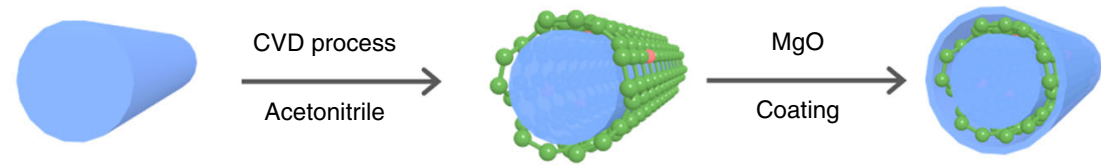

$\mathrm{MgO}$ nanowire

$\mathrm{MgO} / \mathrm{N}$-doped graphene

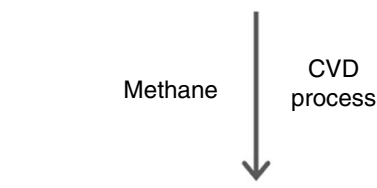

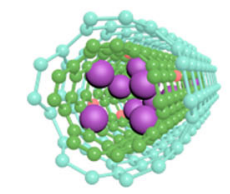

$\mathrm{Sn} /$ double graphene tube
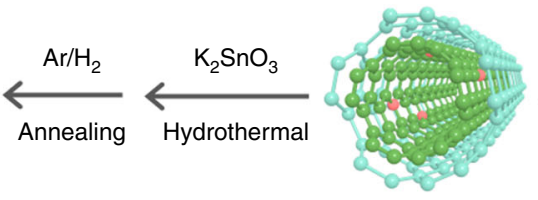

Double graphene tube

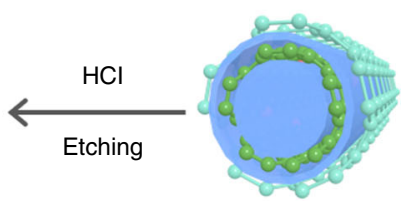

MgO/Double graphene tube

b
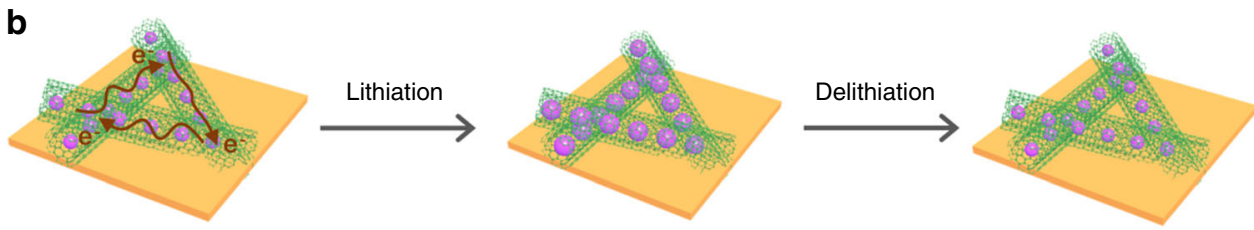

$\mathrm{MgO}$ nanowire

$\mathrm{N}$-doped graphene tube
Graphene tube
Sn nanoparticle

Cu foil

Fig. 1 A schematic illustrating the synthesis of Sn/DGT for high-performance anodes. a A schematic illustration of the synthesis of Sn/DGT composite. b A schematic illustration of the lithiation process of a Sn/DGT electrode, during which Sn nanoparticles are retained within the graphene tubes despite their large-volume change, preserving the electron-conduction networks and integrity of the electrode. 

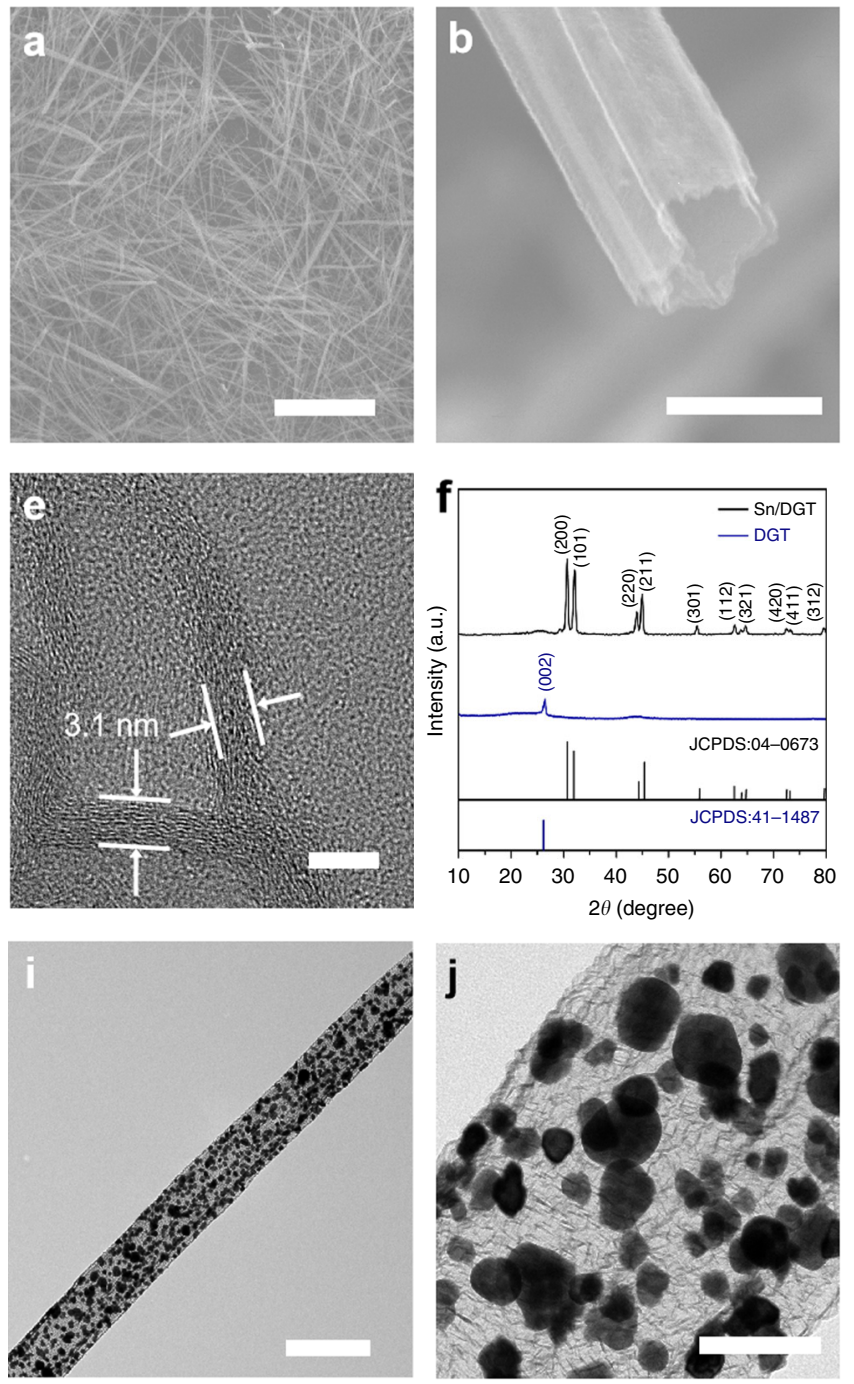
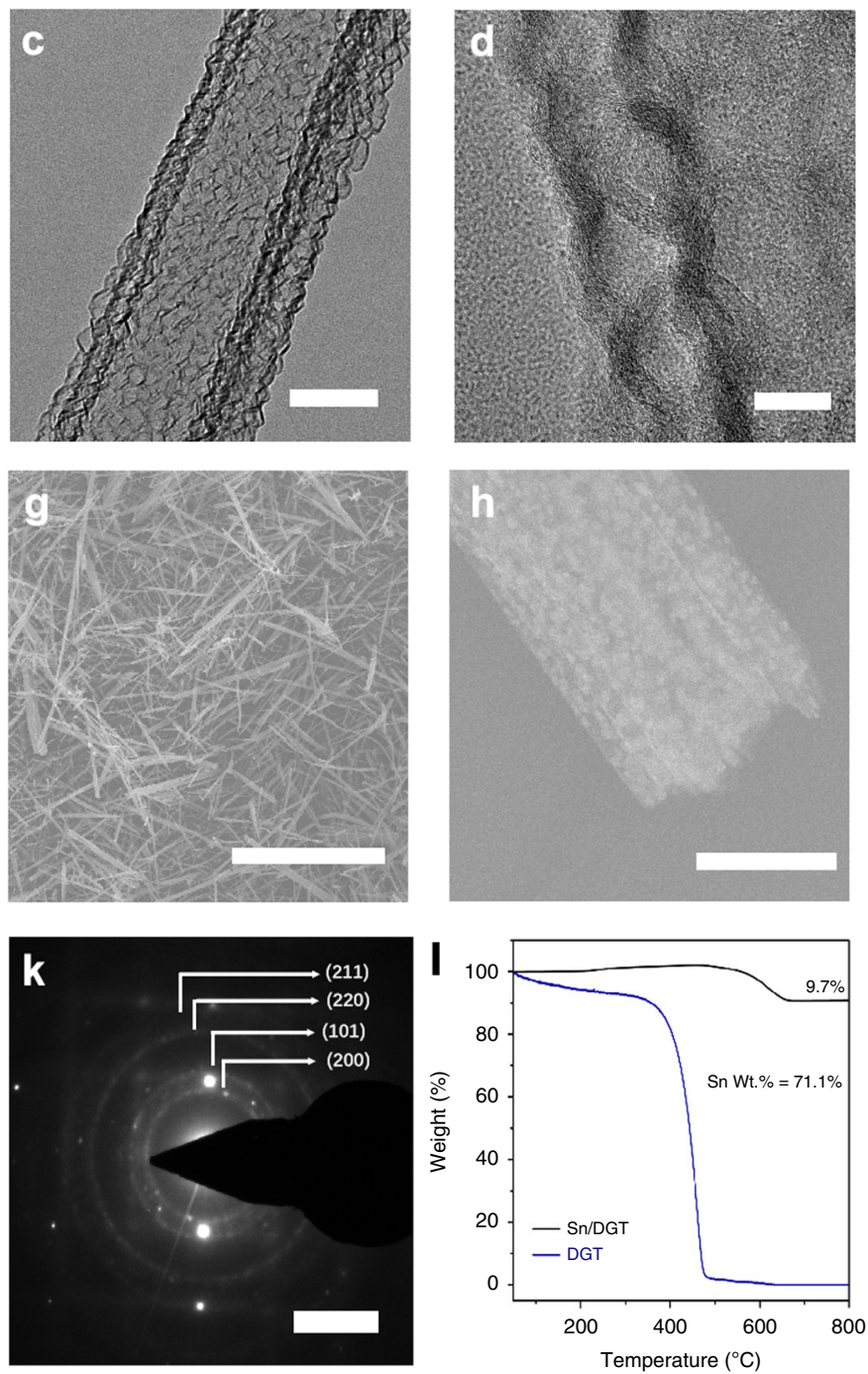

Fig. 2 Morphology and structure of DGT and Sn/DGT. a, b SEM images of DGT. Scale bars: a $10 \mu \mathrm{m}$; b $500 \mathrm{~nm}$, c-e TEM images of DGT. Scale bars: c $200 \mathrm{~nm} ; \mathbf{d} 10 \mathrm{~nm}$; e $5 \mathrm{~nm}, \mathbf{f}$ XRD patterns of DGT and Sn/DGT, $\mathbf{g}$, h SEM images of Sn/DGT. Scale bars: $\mathbf{g} 10 \mu \mathrm{m} ; \mathbf{h} 200 \mathrm{~nm}, \mathbf{i}, \mathbf{j}$ TEM images of Sn/DGT. Scale bars: i $500 \mathrm{~nm} ; \mathbf{j} 100 \mathrm{~nm}$, k selective area electronic diffraction of Sn/DGT. Scale bars: $\mathbf{k} 5$ 1/nm, and I TGA of DGT and Sn/DGT.

shortens their ion-diffusion paths and alleviates the mechanical stress during the alloying/dealloying process. Meanwhile, the tubular structure allows a high loading of Sn nanoparticles, which is critical for high energy density. Note that Sn-carbon composites were also synthesized by infiltrating Sn precursors to carbon scaffolds (e.g., porous carbon particles and carbon fibers) followed by a reduction process ${ }^{26-35}$. In these approaches, it is difficult to assure as-formed Sn particles are confined within the scaffolds, whereas detachment of the Sn particles from the carbon scaffolds could unavoidably result in decay of the capacity.

Here in this work, by confining a high loading of Sn nanoparticles within highly conductive DGT, our strategy avoids the detachment of the Sn nanoparticles from the conductive networks, affording the anodes with high volumetric capacity, outstanding power performance and long cycling life. Asmade $\mathrm{Sn}$ anodes can provide high capability $\left(918 \mathrm{~mA} \mathrm{~h}^{-1}\right.$ or $2532 \mathrm{~mA} \mathrm{~h} \mathrm{~cm}^{-3}$ ), long cycling stability (>95\% reversible capacity retention after 500 cycles), and excellent rate performance $\left(402 \mathrm{~mA} \mathrm{~h} \mathrm{~g}^{-1}\right.$ at current density $\left.20 \mathrm{Ag}^{-1}\right)$. When paired with NCM622, full cells with high energy density (598 $\mathrm{W} \mathrm{h} \mathrm{Kg}^{-1}$ or $1252 \mathrm{~W} \mathrm{~h} \mathrm{~L}^{-1}$ ) are demonstrated, which are 1.4 and 1.9 times higher than those made with commercial graphite anodes, respectively.

\section{Results}

Materials synthesis and characterization. Figure $2 \mathrm{a}-\mathrm{d}$ shows the scanning electron microscopic (SEM) and transmission electron microscopic (TEM) images of DGT, which show an average diameter of $350 \mathrm{~nm}$ and a length between $10 \mu \mathrm{m}$ and $20 \mu \mathrm{m}$ (Fig. 2a). The double-tube structure can be clearly visualized from the SEM image shown in Fig. 2b, which is further confirmed by the TEM image in Fig. 2c. The distance between the inner and outer tube is $\sim 10 \mathrm{~nm}$; meanwhile, porous structure in the tube wall can be clearly observed, providing pathways for the transport of electrolytes (Fig. 2d). Figure 2e shows a higher-magnification TEM image of DGT, indicating the graphene structure has a tubewall thickness of $3.1 \mathrm{~nm}$ (approximately nine layers of graphene). In addition, chemical mapping of the graphene tubes confirms the presence of nitrogen, indicating successful nitrogen doping of the inner graphene tubes (Supplementary Fig. 2).

Figure $2 \mathrm{f}$ shows the X-ray diffraction (XRD) of DGT and Sn/ DGT. DGT exhibits the (002) peak at $\sim 26^{\circ}$, Sn/DGT exhibits

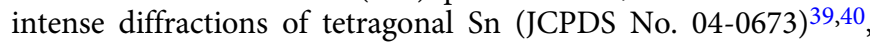
and no diffraction peaks from the graphene tubes can be observed due to its low content. Raman spectra of Sn/DGT show two peaks centered at $1331 \mathrm{~cm}^{-1}$ and $1586 \mathrm{~cm}^{-1}$, attributed from the DGT moiety (Supplementary Fig. 3) ${ }^{41,42}$. Figure $2 \mathrm{~g}$, h shows the SEM 

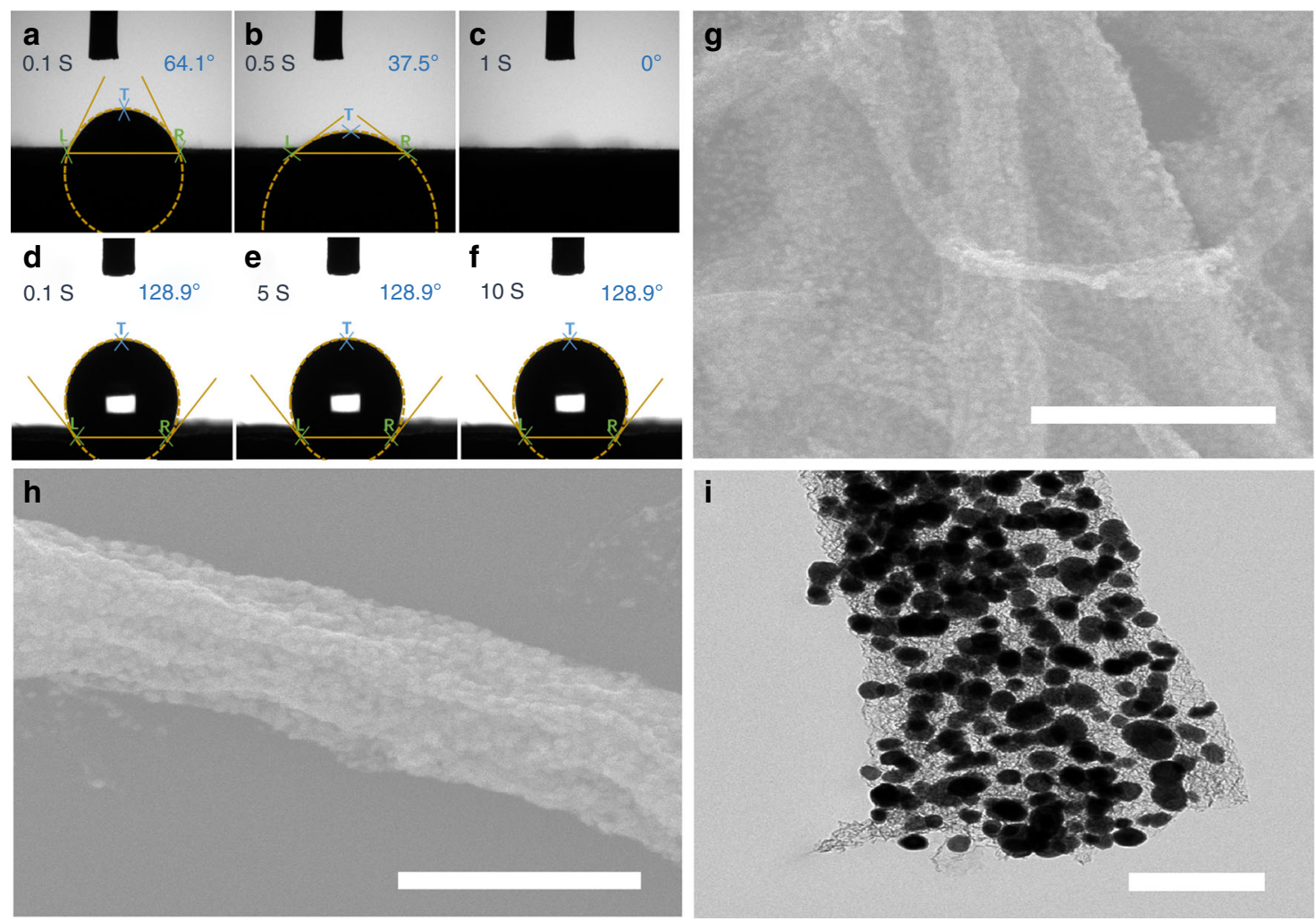

Fig. 3 Wetting process of water on nitrogen-doped and un-doped graphene tubes and the role of biphilicity on the selective growth of SnO $\mathrm{O}_{2}$. Wetting process of water on nitrogen-doped graphene tubes (a-c) and un-doped graphene tubes (d-f). $\mathbf{g}, \mathbf{h}$ SEM and i TEM images of Sn/DGT*. Scale bars: $\mathbf{g} 2 \mu$ m; h $500 \mathrm{~nm} ; \mathbf{i} 200 \mathrm{~nm}$.

images of Sn/DGT, where Sn nanoparticles are encapsulated within the graphene tubes. TEM image suggests that $\mathrm{Sn}$ nanoparticles are uniformly distributed within the DGT (Fig. 2i) with an average diameter of $40 \mathrm{~nm}$ (Fig. 2j). No Sn nanoparticles outside the DGT could be observed. As demonstrated in Supplementary Fig. 4, the Sn nanoparticles have an interplanar distance of $0.29 \mathrm{~nm}$, attributed to the (200) facet of tetragonal $\mathrm{Sn}^{39,40}$. Figure $2 \mathrm{k}$ exhibits the selected-area electron diffraction (SAED) of Sn/DGT confirming the formation of tetragonal-phase Sn. Figure 21 shows the thermal gravimetric analysis (TGA) of DGT and Sn/DGT measured using an air atmosphere. DGT experiences a major weight loss from 400 to $500{ }^{\circ} \mathrm{C}$ due to its oxidation reaction, while the weight of $\mathrm{Sn} / \mathrm{DGT}$ increases before $500{ }^{\circ} \mathrm{C}$ attributed to the oxidation of the Sn nanoparticles. Further increasing the temperature causes oxidation of the DGT moiety, accompanied by a weight loss. The final weight loss of Sn/DGT is around $9.7 \%$, corresponding to a Sn content of $\sim 71.1 \mathrm{wt} \%$.

Figure $3 \mathrm{a}-\mathrm{f}$ shows a wetting process of water on nitrogendoped (A-C) and un-doped (D-F) graphene tubes. The nitrogendoped graphene tubes (the inner tubes of DGT) exhibit an initial contact angle of $64.1^{\circ}$, which is rapidly decreased to $0^{\circ}$ after $1 \mathrm{~s}$, indicating a hydrophilic surface. In contrast, the un-doped graphene tubes (the outer tubes of DGT) show a stable contact angle of $\sim 128.9^{\circ}$, indicating a hydrophobic surface. Such biphilicity (the co-exitance of hydrophilic and hydrophobic tubes) is critical to ensure the encapsulation of Sn nanoparticles within the DGT and avoid their attachment outside the DGT.

Firstly, the biphilicity of DGT allows the aqueous precursor solution to infiltrate to the inner hydrophilic tubes, where tin oxide $\left(\mathrm{SnO}_{2}\right)$ nanoparticles with a tetragonal rutile $\mathrm{SnO}_{2}$ phase (JCPDS No. 41-1445) were formed (Supplementary Fig. 5). Supplementary Fig. 6 shows the SEM and TEM images of a $\mathrm{SnO}_{2} /$ DGT composite. The graphene tubes maintain their tubular structure after the growth of $\mathrm{SnO}_{2}$ nanoparticles (Supplementary Fig. 6a); chemical mapping indicates a uniform distribution of the nanoparticles within the DGT (Supplementary Fig. 6b). Secondly, it appears that $\mathrm{Sn}$ nanoparticles prefer to grow on nitrogen-doped graphene surface than the un-doped graphene surface. To confirm, we prepared double-graphene-tubes that consist an outer hydrophilic graphene tube and an inner hydrophobic graphene tube. Sn nanoparticles were also grown on these tubes using a similar process, resulting in a composite denoted as $\mathrm{Sn} /$ DGT* (Supplementary Figs. 7, 8). As expected, an appreciable amount of $\mathrm{Sn}$ nanoparticles was grown outside the doublegraphene-tubes (Fig. 3g-i), confirming the roles of biphilicity on selective growth of $\mathrm{SnO}_{2}$ nanoparticles within the DGT. Thirdly, although Sn nanoparticles may also be formed in the reaction solution; such nanoparticles could be readily removed during the filtration process, a step used to separate Sn/DGT from the reaction mixture. The ability to confine the growth of $\mathrm{Sn}$ nanoparticles within DGT, as well as the ability to remove free $\mathrm{Sn}$ nanoparticles from the Sn/DGT, is essential to ensure the high performance of such $\mathrm{Sn}$ anodes. For further confirmation, hydrophobic graphene tubes were also synthesized, and the growth of Sn nanoparticles on the hydrophobic graphene tubes could not be observed (Supplementary Fig. 9).

Electrochemical performance. Figure $4 \mathrm{a}$ shows the representative charge/discharge voltage profiles of a Sn/DGT electrode from 0.01 to $2.5 \mathrm{~V}$ (vs. lithium metal) at $0.2 \mathrm{~A} \mathrm{~g}^{-1}$. The electrode shows an initial discharge and charge capacity of $1285 \mathrm{~mA} \mathrm{~h} \mathrm{~g}^{-1}$ and $913 \mathrm{~mA} \mathrm{~h} \mathrm{~g}^{-1}$, corresponding to an initial Coulombic efficiency of $71.1 \%$. The excess discharge capacity could be attributed to the decomposition of the electrolyte, the formation of solid electrolyte interphase (SEI), and to irreversible insertion of Li ions into the $\mathrm{Sn}^{34-37}$. The capacity of the $\mathrm{Sn} / \mathrm{DGT}$ electrode is mainly 
a

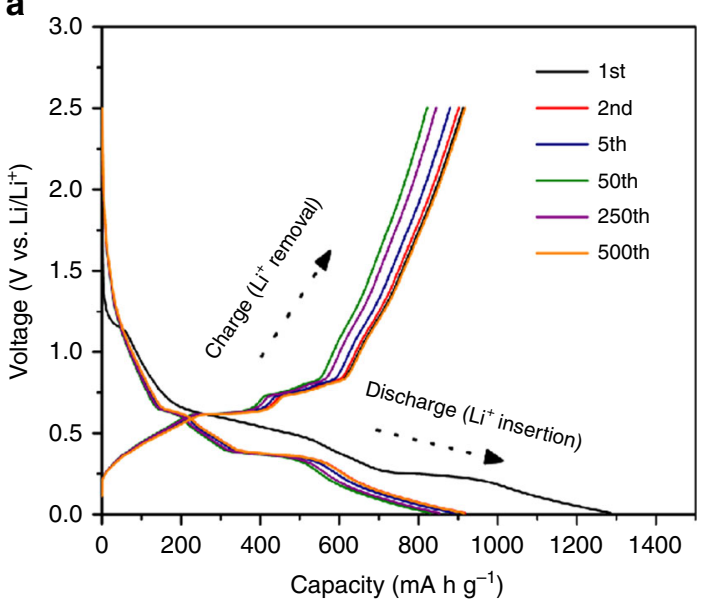

b

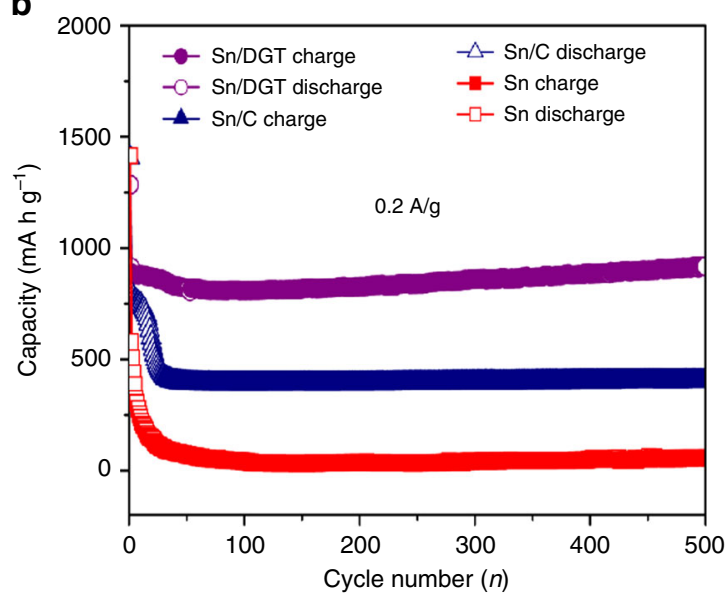

C

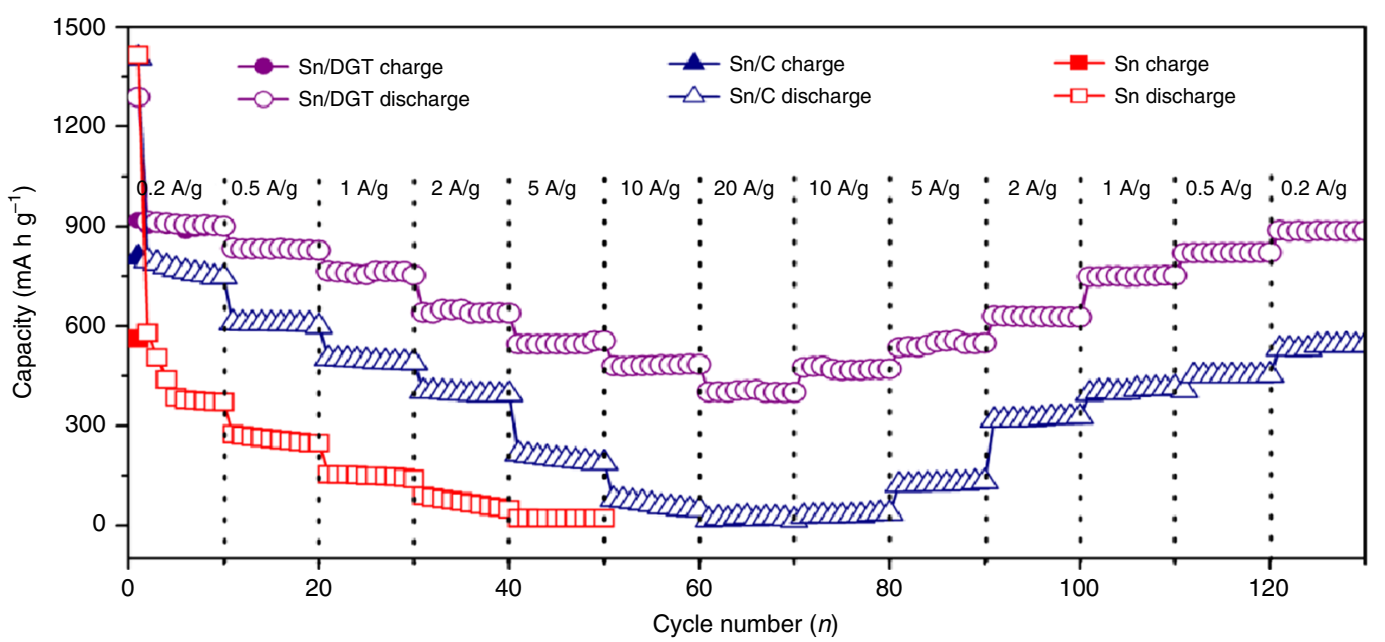

d

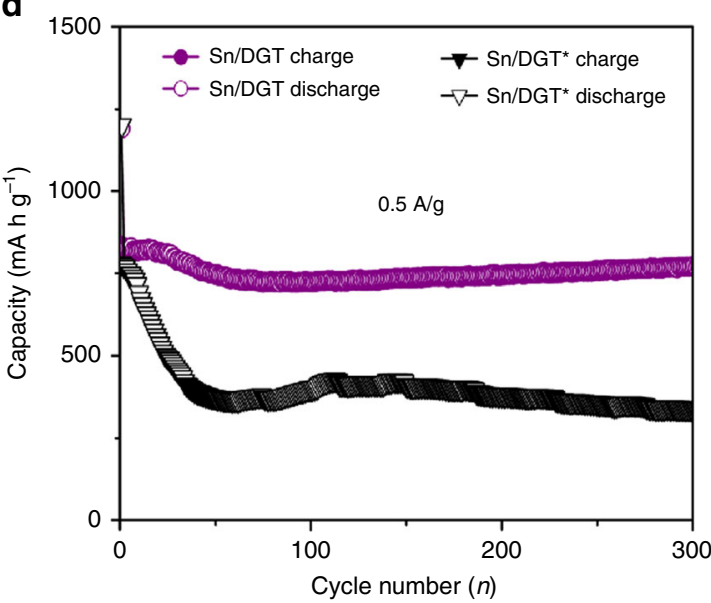

e

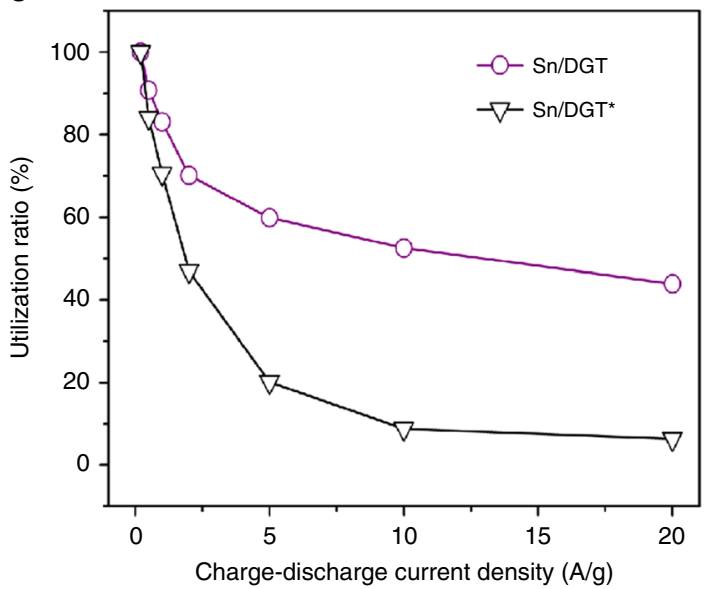

Fig. 4 Electrochemical performance of the Sn/DGT. a Galvanostatic charge-discharge profiles of Sn/DGT from 0.01 to $2.5 \mathrm{~V}$ (versus $\mathrm{Li} / \mathrm{Li}^{+}$) for the $1 \mathrm{st}$, 2nd, 10th, 100th, and 500th cycles at a current density of $0.2 \mathrm{~A} \mathrm{~g}^{-1}$. b Cycling performance (charge/discharge) of the Sn/DGT electrode, Sn/C and Sn electrodes with a mass loading of $2 \mathrm{mg} \mathrm{cm}^{-2}$ at a current density of $0.2 \mathrm{~A} \mathrm{~g}^{-1}$ for 500 cycles, respectively. c The capacity of the Sn/DGT electrode, Sn/C and $\mathrm{Sn}$ electrodes at different current densities. d Cycling performance (charge/discharge) of the Sn/DGT electrode and Sn/DGT* electrode with a mass loading of $2 \mathrm{mg} \mathrm{cm}^{-2}$ at a current density of $0.5 \mathrm{~A} \mathrm{~g}^{-1}$ for 300 cycles. e Utilization of the active material of the Sn/DGT electrode and Sn/DGT* electrode at different charge-discharge current densities.

contributed by $\mathrm{Li}$ insertion at voltage below $0.5 \mathrm{~V}$ (vs. $\mathrm{Li}^{+} / \mathrm{Li}$ ), which ensures a high full-cell voltage and high energy density ${ }^{43}$.

As shown in Fig. 4a, the electrode retains a capacity of $918 \mathrm{~mA}$ $\mathrm{h} \mathrm{g}^{-1}$ after 500 cycle, indicating an excellent cycling stability. To further assess the cycling stability of Sn/DGT, electrodes made from commercial Sn particles, as well as a Sn-carbon composite (denoted as $\mathrm{Sn} / \mathrm{C}$ ) was also examined. The $\mathrm{Sn} / \mathrm{C}$ was synthesized by polymerizing dopamine-hydrochloride on commercial $\mathrm{Sn}$ particles followed by carbonization (Supplementary Figs. 10-12). Figure $4 \mathrm{~b}$ compares the capacity of the electrodes made from $\mathrm{Sn}$ / 
DGT, Sn/C, and Sn particles, respectively. After cycling for 500 cycles at a current density of $0.2 \mathrm{~A} \mathrm{~g}^{-1}$, the Sn/DGT electrode still retains a high Coulombic efficiency $(>99 \%)$ and a high capacity of $916 \mathrm{~mA} \mathrm{~h} \mathrm{~g}^{-1}$, which is 4-folds and 16-folds higher than that of the $\mathrm{Sn} / \mathrm{C}\left(201 \mathrm{mAh}^{-1}\right)$ and $\mathrm{Sn}\left(58 \mathrm{mAh}^{-1}\right)$ electrode, respectively. Meanwhile, the capacity of the Sn/DGT electrode increases with time possibly due to a continuous activation process $^{36-38}$.

The rate capability of the Sn/DGT electrodes were evaluated at the current densities of $0.2,0.5,1,2,5$, and $10 \mathrm{~A} \mathrm{~g}^{-1}$, which provides a capacity of $916,831,761,642,548$, and $481 \mathrm{~mA} \mathrm{~h} \mathrm{~g}^{-1}$, respectively (Fig. 4c). Even with a higher current density of $20 \mathrm{~A} \mathrm{~g}^{-1}(\sim 20 \mathrm{C})$, the electrode can still provide a remarkably high capacity of $402 \mathrm{mAg} \mathrm{h}^{-1}$. Returning the cycling current density to $0.2 \mathrm{~A} \mathrm{~g}^{-1}$, the capacity is recovered to $913 \mathrm{~mA} \mathrm{~g} \mathrm{~h}^{-1}$, indicating an outstanding rate capability ${ }^{44}$. The capacity of the composite is contributed by the Sn and DGT moieties. At a voltage window of $0.01-2.5 \mathrm{~V}$, a DGT electrode exhibits a capacity of $712,665,592,551,474,371$, and $252 \mathrm{~mA} \mathrm{~h} \mathrm{~g}^{-1}$ at the current density of $0.2,0.5,1,2,5,10$, and $20 \mathrm{~A} \mathrm{~g}^{-1}$, respectively (Supplementary Fig. 16). Considering the Sn/DGT composite contains $29 \mathrm{wt} \%$ graphene, the capacity contributed by DGT can be estimated as 206, 192, 172, 160, 137, 108, and $73 \mathrm{~mA} \mathrm{~h} \mathrm{~g}{ }^{-1}$, respectively. Such SEI layer could be partly decomposed during the charge process, contributing to the charge capacity 45 . And the other is the improved lithium storage capacity by the synergetic effect between conducting DGT and Sn NPs, which is responsible for the excellent electrochemical performance of the overall electrode via the maximum utilization of electrochemically active DGT and nanosized $\mathrm{Sn}^{31,46}$.

The outstanding rate capability can be attributed to the excellent electrical conductivity and fast diffusion of lithium ions ${ }^{47}$. For further confirmation, Supplementary Fig. 13 compares the Nyquist plots of the Sn/DGT, Sn/C, and Sn electrodes, where the Sn/DGT electrode exhibits a much smaller resistance than the others. Supplementary Fig. 14 provides an equivalent circuit, which consists of a solution resistance $\left(R_{s}\right)$, a charge-transfer resistance $\left(R_{c t}\right)$, a contact resistance $\left(R_{f}\right)$, and a Warburg impedance $\left(Z_{w}\right)$. As depicted in Supplementary Table 1 , the calculated $R_{c t}$ and $R_{f}$ values of the $S n / D G T$ electrode are significantly lower than those of the $\mathrm{Sn} / \mathrm{C}$ and $\mathrm{Sn}$ electrodes. It is interesting to compare the performance of Sn/DGT electrodes with and without carbon black additive. It was found that the electrode without carbon black shows a capacity of $907 \mathrm{~mA} \mathrm{~h} \mathrm{~g}^{-1}$ at $0.2 \mathrm{~A} \mathrm{~g}^{-1}$, whereas increasing the current density deteriorates the rate performance (Supplementary Fig. 15). This result suggests that the use of nanosized carbon black is still necessary in order to construct highly effective conductive networks ${ }^{40}$, despite the excellent electrical conductivity of the DGT.

The outstanding cycling stability and rate performance are contributed from the ability to encapsulate the $\mathrm{Sn}$ nanoparticles within the highly conductive and robust graphene tubes. Figure $4 \mathrm{~d}$ compares the cycling stability of Sn/DGT and Sn/DGT* (mass loading of $2 \mathrm{mg} \mathrm{cm}^{-2}$ ) at current density of $0.5 \mathrm{Ag}^{-1}$, which show a similar initial discharge and charge capacity of $1200 \mathrm{~mA} \mathrm{~h}$ $\mathrm{g}^{-1}$ and $810 \mathrm{~mA} \mathrm{~h}^{-1}$. However, Sn/DGT* contains a significant amount of $\mathrm{Sn}$ nanoparticles outside the graphene tubes (see Fig. 3), which can be easily detached from the graphene tubes during the cycling, resulting in a capacity decay to $337 \mathrm{~mA} \mathrm{~h} \mathrm{~g}^{-1}$ after 300 cycles. Whereas Sn/DGT still retains a high capacity of $769 \mathrm{~mA} \mathrm{~h} \mathrm{~g}^{-1}$, confirming the encapsulation of the Sn nanoparticles do critically contribute to the cycling stability. Supplementary Fig. 17 shows TEM images of the Sn/DGT anode after cycling at $5 \mathrm{Ag}^{-1}$ for 500 cycles, confirming that the $\mathrm{Sn}$ nanoparticles were still confined within the graphene tubes. The electrode exhibits the first-cycle discharge and charge capacities of
536 and $722 \mathrm{mAh} \mathrm{g}^{-1}$ at the current density of $5 \mathrm{Ag}^{-1}$, respectively, giving a first-cycle Coulombic efficiency of $74.1 \%$ (Supplementary Fig. 17a), which increases to greater than $98 \%$ in the second cycle and to around $99.9 \%$ after 500 cycles (the high first-cycle capacity is probably due to SEI formation). Note that the accurate measurement of the Coulombic efficiency of half cells is a critical factor to predict the cycle life of full cells. Figure $4 \mathrm{e}$ further plots the utilization of the active material versus the charge-discharge current density of the Sn/DGT and Sn/DGT* electrodes. The utilizations are estimated by normalizing the specific capacity of the electrodes at different charge-discharge current densities (the slopes of the lines) vs. the specific capacity at $0.2 \mathrm{~A} \mathrm{~g}^{-1}$. As shown, the active-material utilization decreases with increasing charge-discharge current density, which is $60 \%, 52 \%$, and $43 \%$ for the Sn/DGT electrode and $20 \%, 9 \%$, and $6 \%$ for the Sn/DGT* electrode at 5, 10, and $20 \mathrm{~A} \mathrm{~g}^{-1}$, respectively. To further assess the performance of the Sn/DGT electrodes, a comparison between the Sn/DGT electrode and other Sn electrodes reported is also provided (Supplementary Table 2).

To further probe the outstanding electrode performance, the lithiation and delithiation process of Sn/DGT were probed by in situ TEM (Supplementary Fig. 18 and Supplementary Movies 1, 2). Figure 5 shows the low-magnification (a-e) and high-magnification ( $\mathrm{f}-\mathrm{j}$ ) TEM images of a Sn/DGT tube during the lithiation and delithiation. The diameter of the graphene tube remains unchanged $(480 \mathrm{~nm})$, whereas the $\mathrm{Sn}$ nanoparticles reversibly expand and shrink during the lithiation and delithiation, of which the change of the particle size are plotted in Fig. 5k-o, respectively. As shown, despite the volume change, these particles remain confined within the graphene tubes. Figure 5p-t shows the selective area electronic diffraction of Sn/ DGT during this process. The Sn nanoparticles exhibit a tetragonal crystal structure $(a=5.8316 \AA, c=3.1813 \AA$, space group 141) prior to the lithiation (Fig. 5p). After lithiation for $300 \mathrm{~s}$, the diffraction spots are changed to diffraction rings, consistent with a polycrystalline $\mathrm{Li}_{\mathrm{x}} \mathrm{Sn}$ phase. The rings corresponding to a $d$-spacing of $0.192 \mathrm{~nm}$ and $0.237 \mathrm{~nm}$ are likely attributable to $\mathrm{Li}_{5} \mathrm{Sn}_{2}$, while the ring corresponding to a $d$ spacing of $0.327 \mathrm{~nm}$ is likely attributable to $\mathrm{Li}_{7} \mathrm{Sn}_{3}$ phase (Fig. 5q). After lithiation for $600 \mathrm{~s}$, the $\mathrm{Li}_{\mathrm{x}} \mathrm{Sn}$ phase was converted to the $\mathrm{Li}_{4.4} \mathrm{Sn}$ phase, corresponding to the diffraction rings with the $d$-spacings of $0.232,0.379$, and $0.452 \mathrm{~nm}$ (Fig. $5 \mathrm{r}$ ). The subsequent delithiation process reverses the $\mathrm{Li}_{4.4} \mathrm{Sn}$ phase sequentially to $\mathrm{Li}_{\mathrm{x}} \mathrm{Sn}$ (Fig. 5s) and to tetragonal Sn (Fig. 5t). This observation confirms a reversible phase transformation of the $\mathrm{Sn}$ nanoparticles during the lithiation and delithiation, which are confined with the highly conductive and robust graphene tubes and leads to the outstanding cycling stability and rate performance observed.

To evaluate that feasibility of adapting Sn/DGT for commercial use, electrodes with different areal mass loadings were fabricated by changing the thickness of the electrode. Figure 6a shows the areal capacity $v s$. the areal mass loading of the electrodes at different current densities. The areal capacity increases linearly with the areal mass loading at relatively low current densities (e.g., $<5 \mathrm{~A} \mathrm{~g}^{-1}$ ); whereas further increasing the current density deviates the linear relation. Figure $6 \mathrm{~b}$ plots the areal capacity vs. the areal current density, where the electrode with a mass loading of $6 \mathrm{mg} \mathrm{cm}^{-2}$ exhibits an areal capacity of $5.4,4.9,4.4$, and $3.7 \mathrm{~mA} \mathrm{~h} \mathrm{~cm}^{-2}$ at the areal current density of $1.6,4,8$, and $16 \mathrm{~mA} \mathrm{~cm}^{-2}$, respectively. For comparison, commercial graphite anodes generally provide areal capacities in the range of $2.5-3.5 \mathrm{~mA} \mathrm{~h} \mathrm{~cm}^{-2}$ at a current-density range of $0.3-1.86 \mathrm{~mA} \mathrm{~cm}^{-2}$ (see the marked area marked in Fig. $\left.6 \mathrm{~b}\right)^{48}$. Clearly, Sn/DGT electrodes well outperform the commercial 

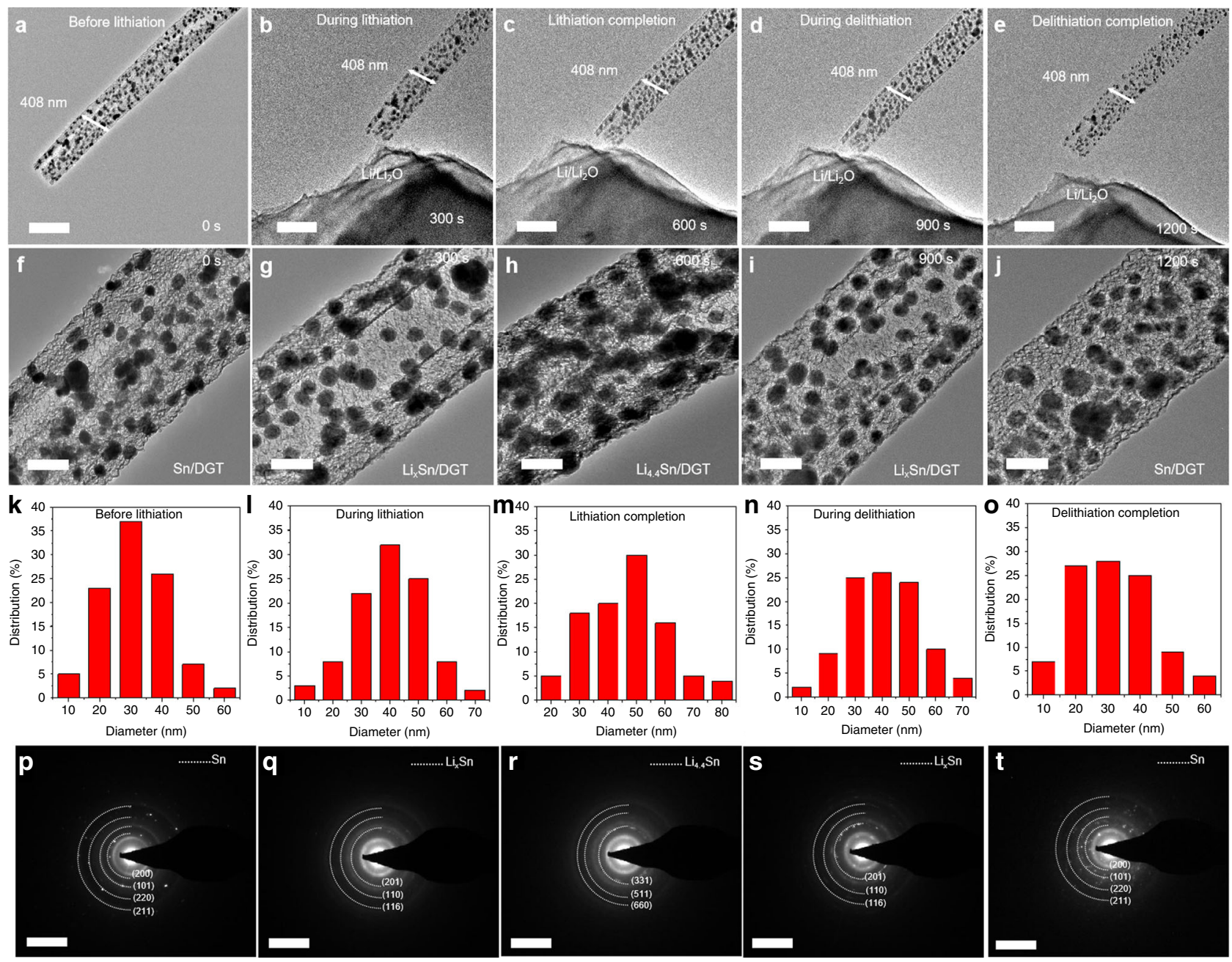

Fig. $\mathbf{5}$ In situ TEM observation of Sn/DGT during a lithiation-delithiation cycle. a-e Time-lapse low magnification and $\mathbf{f - j}$ high-magnification TEM images showing the lithiation and delithiation of a Sn/DGT electrode (Supplementary Movies 1, 2). During this process, the Sn nanoparticles experienced volume expanding and shrinking, yet remained within the graphene tube, of which the structure and dimension remains unchanged. Scale bars: a 500 nm; b $500 \mathrm{~nm}$; $500 \mathrm{~nm}$; d $500 \mathrm{~nm}$; e $500 \mathrm{~nm} ; \mathbf{f} 100 \mathrm{~nm} ; \mathbf{g} 100 \mathrm{~nm} ; \mathbf{h} 100 \mathrm{~nm}$; $100 \mathrm{~nm}$; j $100 \mathrm{~nm}$. k-o Size analysis of the Sn nanoparticles during the lithiation-delithiation cycle obtained using a semi-automated sizing approach. p-t The selective area electron diffraction patterns of the Sn nanoparticles during the lithiation-delithiation cycle. Scale bars: p $51 / \mathrm{nm}$; q $51 / \mathrm{nm} ; \mathbf{r} 51 / \mathrm{nm} ; \mathbf{s} 51 / \mathrm{nm}$; t $51 / \mathrm{nm}$.

graphite anodes. Furthermore, these thick Sn/DGT electrodes also exhibit outstanding cycling stability. For example, after cycling a current density of $2 \mathrm{Ag}^{-1}$ for 200 cycles, these electrodes retain over $90 \%$ of their initial capacity (Supplementary Fig. 19a) with low charge-transfer resistance indicated by their electrochemical impendence spectra (Supplementary Fig. 19b).

Figure $6 c$ plots the areal capacity vs. the areal current density of representative anode materials, including commercial graphite, graphene, $\mathrm{Li}_{4} \mathrm{Ti}_{5} \mathrm{O}_{12}, \mathrm{Sn} / \mathrm{C}$, and $\mathrm{Si} / \mathrm{C}$-based composites. As shown, graphene aerogel, popcorn-like graphene ${ }^{49-51}$, and edge-activated graphite exhibit higher areal capacities and improved rate performance that graphite. Incorporating high-capacity $\mathrm{Si}$ to graphene and graphite further increases their areal capacity at low current density. However, inherently limited by the slow reaction between silicon and lithium, the capacity is decreased rapidly with increasing the current density. The Sn/DGT electrodes well outperformances the reported electrodes in both areal capacity and rate performance. For example, the Sn/DGT anode can supply a high areal capacity over $4 \mathrm{mAh} \mathrm{cm}-2$ at the areal current density of $10 \mathrm{~mA} \mathrm{~cm}^{-2}$, which is the best-known values for the anodes reported $32,35,41,49-54$.
Figure 6d compares the volumetric capacities of representative anode materials vs. their gravimetric capacity, including commercial graphite, $\mathrm{Li}_{4} \mathrm{Ti}_{5} \mathrm{O}_{12}$, Sn-based, and Si-based anodes reported $12,55-63$. The volumetric capacities of the anode materials (active material only) were estimated based on the tap density and gravimetric specific capacity in un-lithiated state. Sn/DGT shows a tap density around $2.76 \mathrm{~g} \mathrm{~cm}^{-3}$, corresponding a volumetric capacity of $2532 \mathrm{~mA} \mathrm{~h} \mathrm{~cm}^{-3}$ and $1106 \mathrm{~mA} \mathrm{~h} \mathrm{~cm}^{-3}$ for the Sn/DGT composite at a current density of $0.2 \mathrm{~A} \mathrm{~g}^{-1}$ and $20 \mathrm{~A} \mathrm{~g}^{-1}$, respectively (based on the tap density) (Supplementary Fig. 20). The electrode retains a high volumetric capacity of $2528 \mathrm{~mA} \mathrm{~h} \mathrm{~cm}^{-3}$ after 500 cycles under a current density of $0.2 \mathrm{~A} \mathrm{~g}^{-1}$ (Supplementary Fig. 21). The volumetric capacity of the Sn/DGT electrodes well outperformances the reported anodes, despite their gravimetric capacity is less than the silicon granule ${ }^{12}$ and $3 \mathrm{D}$ silicon membrane ${ }^{63}$.

Note that it is more accurate and meaningful to present the volumetric capacity of anode materials or electrodes in fulllithiation state ${ }^{7}$. However, due to the lack of data in specific density of the anode materials that are in full-lithiation state, it is difficult to compare the volumetric capacity of the anode 
a

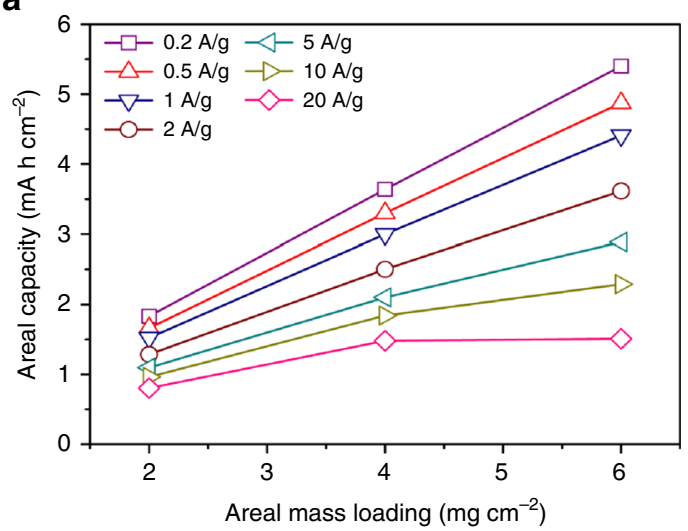

C

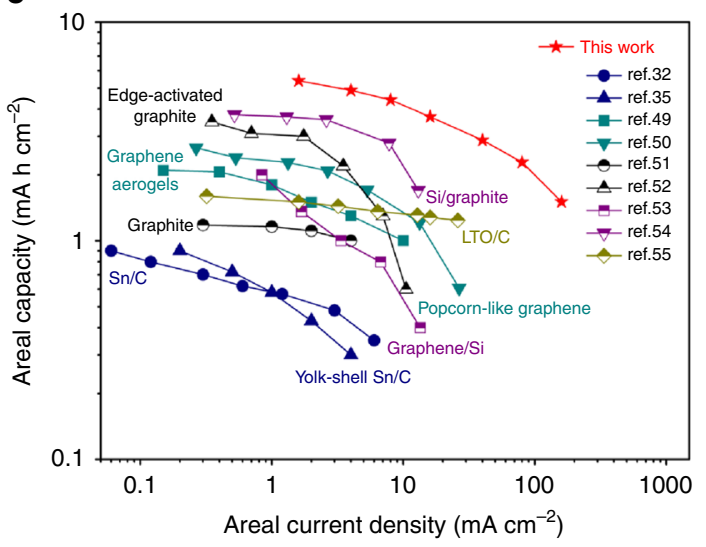

e

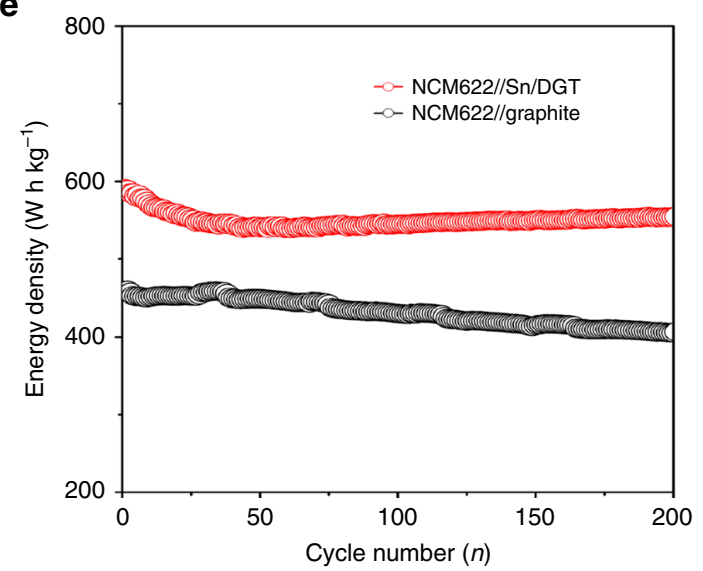

b

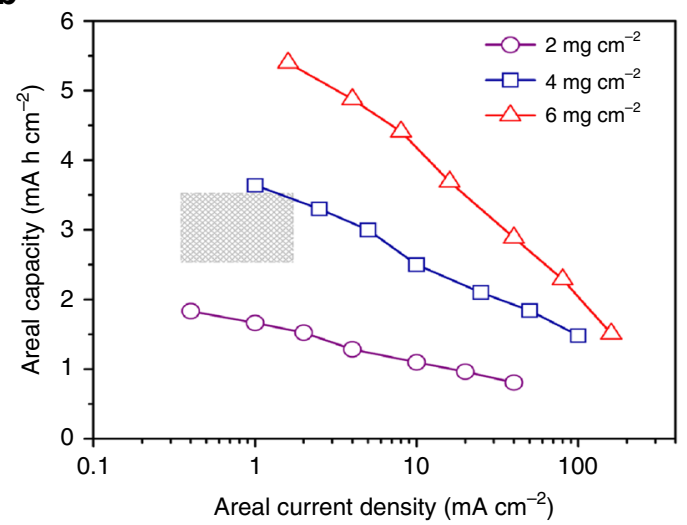

d

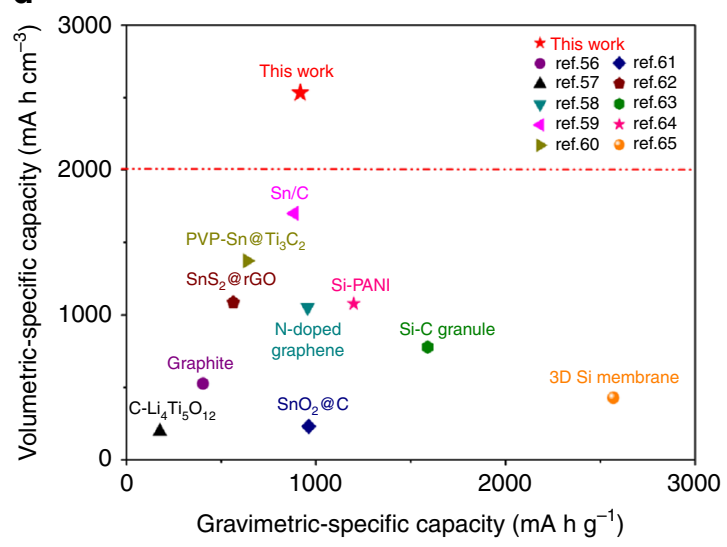

$\mathbf{f}$

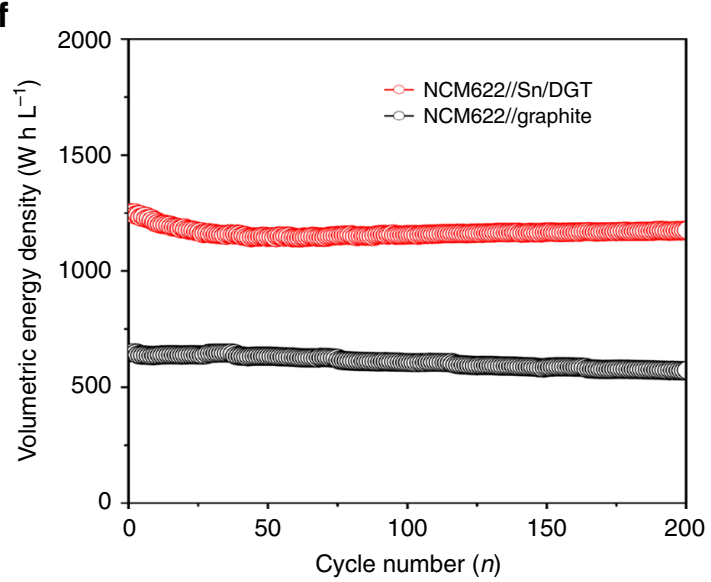

Fig. 6 Feasibility of adapting Sn/DGT as high-performance anodes for commercial batteries. a The areal capacity of Sn/DGT electrodes with mass loading of 2, 4, and $6 \mathrm{mg} \mathrm{cm}^{-2}$ at different charge-discharge current densities. $\mathbf{b}$ The areal capacity of Sn/DGT electrodes vs. the areal current density of the $\mathrm{Sn} / \mathrm{DGT}$ anodes with a mass loading of 2,4 , and $6 \mathrm{mg} \mathrm{cm}^{-2}$, respectively. The gray area marked represents the range of areal capacity of commercial graphite anodes. c A comparison of the areal performance metrics of Sn/DGT electrode (mass loadings of $6 \mathrm{mg} \mathrm{cm}^{-2}$ ) with representative anodes reported, including the anodes from graphite, graphene, $\mathrm{Li}_{4} \mathrm{Ti}_{5} \mathrm{O}_{12}$ (LTO), $\mathrm{Sn} / \mathrm{C}$ and $\mathrm{Si} / \mathrm{C}$. d A comparison of the specific volumetric capacity of Sn/DGT electrode (active materials only) with reported anode materials, including the anodes of graphite, LTO, Sn/C, and Si/C. e The gravimetric and $\mathbf{f}$ volumetric energy density of a cell consisting with a NCM622 cathode and a Sn/DGT anode, as well as a cell consisting with a NCM622 cathode and graphite anode.

materials in full-lithiation state. Meanwhile, most literatures did not provide the thickness of the electrodes (un-lithiated or lithiated state), making it difficult to compare the volumetric capacity of the whole electrodes. To be more accurate, the thickness of the Sn/DGT electrodes (mass loading of 2, 4, and 6 $\mathrm{mg} \mathrm{cm}-2$ ) was measured before and after lithiation using SEM (Supplementary Fig. 22). The electrodes experience a thickness change of $\sim 18 \%$ upon lithiation and well retain their structure integrity. Under a current density of $0.2 \mathrm{~A} \mathrm{~g}^{-1}$, these electrodes before and after lithiation exhibit a volumetric capacity of $1146 \mathrm{~mA} \mathrm{~h} \mathrm{~cm}^{-3}$ and $963 \mathrm{~mA} \mathrm{~h} \mathrm{~cm}{ }^{-3}$ with a mass loading of $2 \mathrm{mg} \mathrm{cm}^{-2}, 1210 \mathrm{~mA} \mathrm{~h} \mathrm{~cm}^{-3}$, and $1037 \mathrm{~mA} \mathrm{~h} \mathrm{~cm}^{-3}$ with a mass loading of $4 \mathrm{mg} \mathrm{cm}^{-2}$, and $1197 \mathrm{~mA} \mathrm{~h} \mathrm{~cm}^{-3}$, and $1017 \mathrm{~mA} \mathrm{~h} \mathrm{~cm}^{-3}$ with a mass loading of $6 \mathrm{mg} \mathrm{cm}^{-2}$, respectively. Such volumetric capacities are comparable to the record high volumetric value of Sn-based electrodes (Supplementary Table 3). 
Finally, to demonstrate the viability of using Sn/DGT as the high-performance anodes, full cells were assembled using a commercial cathode material, lithium-nickel cobalt manganese oxide (NCM622) with a bulk density $\left(4.5 \mathrm{~g} \mathrm{~cm}^{-3}\right)$. For comparison, control cells were also assembled using a graphite anode and a NCM622 cathode. Figure 6e shows the cycling performance of the NCM622//Sn/DGT cell, displaying a gravimetric energy density of $590 \mathrm{~W} \mathrm{~h} \mathrm{Kg}{ }^{-1}$ with a capacity retention of $93 \%$ over 200 cycles (based on the total mass of electrode materials), which is significantly higher than that of the NCM622//graphite cell. In this cell configuration, the areal capacity of the electrode is $3.2 \mathrm{~mA}$ $\mathrm{h} \mathrm{cm}^{-2}$ and the thickness of the cell (including the anode, cathode, current collector, and separator) is $\sim 92 \mu \mathrm{m}$ (Supplementary Fig. 23a). The volumetric energy density of the cell is estimated to be $1252 \mathrm{Wh} \mathrm{L} \mathrm{L}^{-1}$ (Supplementary Fig. 23b). This value represents a near two-fold increase from that of the commercial NCM622//graphite cell calculated based on the same metric $\left(647 \mathrm{~W} \mathrm{~h} \mathrm{~L}^{-1}\right)$. Note that the current-state-of-art commercial LIBs (e.g., LIBs for microelectronics and electric vehicles) generally possess a volumetric energy density from $600 \mathrm{~W} \mathrm{~h} \mathrm{~L}^{-1}$ to $700 \mathrm{Wh}$ $\mathrm{L}^{-1}$, which is consistent with that of the control cell. This comparison further confirms the feasibility of fabricating LIBs with significantly improved volumetric energy density using Sn/DGT as the anodes. It is also worth noting that the volumetric energy density of the NCM622//Sn/DGT cell is still around 1.8 times higher than that of the NCM622//graphite cell $\left(602 \mathrm{~W} \mathrm{~h} \mathrm{~L}^{-1}\right)$ after 200 cycles (Fig. 6f). The ability to fabricate full cells with such high gravimetric and volumetric energy density, as well as long cycling life, indeed opens a new avenue towards high-performance LIBs for microelectronic and electrical vehicle application.

\section{Discussion}

In summary, we have developed $\mathrm{Sn}$ anodes with both high gravimetric and volumetric capacities. This is achieved simply by encapsulating Sn nanoparticles, a metal with high gravimetric and volumetric capacity, within highly conductive and robust graphene tubes. Despite their large-volume change during cycling, the Sn nanoparticles are confined with the graphene tubes, ensuring an outstanding rate performance and long cycling life. Meanwhile, through creating the double-graphene-tubes with biphilic nature, we minimized the amount of free Sn nanoparticles in the electrodes, which could have caused rapid capacity decay upon detaching from the graphene tubes. This strategy significantly improves the gravimetric energy density and volumetric energy density of LIBs. We expect that adopting such Sn anodes could potentially double the volumetric energy density of the LIBs in the current market. Meanwhile, the selective-growth strategy can be extended to synthesize a variety of functional materials for a broad range of applications.

\section{Methods}

Preparation of Sn/DGT. A solution of magnesium acetate was made by adding $12 \mathrm{~g}$ magnesium acetate to $80 \mathrm{~mL}$ distilled water. A solution of urea made by adding $1.2 \mathrm{~g}$ urea to $20 \mathrm{~mL}$ water was then dropped into the magnesium acetate solution and stirred for $1 \mathrm{~h}$. Subsequently, the above solution was sealed in a 200 $\mathrm{mL}$ Teflon-lined autoclave and maintained at $180^{\circ} \mathrm{C}$ for $2 \mathrm{~h}$. As-formend $\mathrm{Mg}(\mathrm{OH})_{2}$ was filtrated, washed with ethanol, dried in vacuum at $100^{\circ} \mathrm{C}$, and calcined at $600^{\circ}$ $\mathrm{C}$ for $6 \mathrm{~h}$ in air to obtain the MgO template.

The chemical vapor deposition (CVD) was conducted by placing the template in a quartz boat in a horizontal quartz tube. Under a flow of $\mathrm{Ar}\left(1000.0 \mathrm{~mL} \mathrm{~min}^{-1}\right)$ and $\mathrm{H}_{2}\left(300.0 \mathrm{~mL} \mathrm{~min}^{-1}\right)$, the reactor was heated to $900{ }^{\circ} \mathrm{C}$, and another Ar stream $\left(150.0 \mathrm{~mL} \mathrm{~min}^{-1}\right)$ flowing through a flask of acetonitrile was flowed into the system for $10 \mathrm{~min}$ to obtain nitrogen-doped graphene coating on the template. As-formed $\mathrm{N}$-doped graphene was then dispersed in $100 \mathrm{~mL}$ deionized water, which contain $0.5 \mathrm{~g}$ of $\mathrm{Mg}\left(\mathrm{NO}_{3}\right)_{2} \cdot 2 \mathrm{H}_{2} \mathrm{O}$ and $0.2 \mathrm{~g}$ of urea, and sonicated for $30 \mathrm{~min}$. Then, the mixture was refluxed at $90^{\circ} \mathrm{C}$ for $24 \mathrm{~h}$, washed and dried at $80^{\circ} \mathrm{C}$ overnight. Asobtained product was coated with graphene using $\mathrm{CH}_{4}\left(400.0 \mathrm{~mL} \mathrm{~min}^{-1}\right)$ as the precursor at $1000{ }^{\circ} \mathrm{C}$ for $10 \mathrm{~min}$. Finally, the obtained samples were washed using hydrochloric acid solution $\left(1 \mathrm{~mol} \mathrm{~L}^{-1}\right)$ to obtain the double-graphene tubes (DGT).
The encapsulation of the Sn nanoparticles within the graphene tubes was achieved following the following steps. $60 \mathrm{mg}$ DGT was added in $60 \mathrm{~mL}$ of distilled water and sonicated for $30 \mathrm{~min}$, in which $0.5 \mathrm{~g} \mathrm{~K}_{2} \mathrm{SnO}_{3} \cdot 3 \mathrm{H}_{2} \mathrm{O}$ was dissolved and stirred for $1 \mathrm{~h}$. The solution was then transferred to a $100 \mathrm{~mL}$ Teflon-lined autoclave, which was maintained at $180^{\circ} \mathrm{C}$ for $12 \mathrm{~h}$. As-formed samples were obtained by centrifugation and filtration, dried under $80^{\circ} \mathrm{C}$ overnight, and annealed at $650{ }^{\circ} \mathrm{C}$ in a gas mixture of $\mathrm{Ar}(95 \%) / \mathrm{H}_{2}(5 \%)$ for $10 \mathrm{~h}$.

Preparation of Sn/C. The carbon-coated Sn nanoparticles were prepared by the polymerization of dopamine-hydrochloride on commercial $\mathrm{Sn}$ particles with a weight ratio of $2: 1\left(\mathrm{Sn}: \mathrm{C}\right.$ ), and followed by the carbonization at $750{ }^{\circ} \mathrm{C}$ for $6 \mathrm{~h}^{17}$.

Material characterization. The morphology and structure of the as-prepared products were conducted by field-emission scanning electron microscopy (FESEM, FEI Nova 430), transmission electron microscopy and high-resolution transmission electron microscopy (HRTEM, FEI Titan STEM). Powder X-ray diffraction was measured on Rigaku Miniflex II diffractometer with $\mathrm{Cu}$ Ka radiation operated at $30 \mathrm{kV}$ and $15 \mathrm{~mA}$. Raman spectroscopy was performed with Renishaw 2000 System. The TGA was determined on an SDT Q600 thermoanalyzer under air. In situ TEM was carried out using a FEI Titan microscope operated at $300 \mathrm{kV}$.

Electrochemical measurement. The samples were mixed with carboxymethyl cellulose (CMC) binder and Super P carbon black to obtain uniform slurry at the weight ratio of $8: 1: 1$. Then the slurries were coated onto copper foil and dried in a vacuum oven under $120^{\circ} \mathrm{C}$ for $24 \mathrm{~h}$. The electrodes were cut into a round shape with a diameter of $1.2 \mathrm{~cm}$ circular pieces. To measure the performance, CR2025 type coin cells were assembled using Li metal foil as the counter electrode and $1 \mathrm{M}$ $\mathrm{LiPF}_{6}$ in ethyl carbonate/dimethyl carbonate $(1: 1 \mathrm{v} / \mathrm{v})$ as electrolyte.

The charge-discharge properties were measured using Land Battery Test System (LAND CT2001A) within a voltage window from 0.01 to $2.5 \mathrm{~V}$ (versus $\mathrm{Li}^{+} / \mathrm{Li}$ ) at room temperature. Electrochemical impedance measurement was evaluated in a range of $0.01-10 \mathrm{MHz}$ at $10 \mathrm{mV}$ with perturbation amplitude of $10 \mathrm{mV}$ on the cells at open circuit potential. The capacities were calculated according to the total weight of the composites ( $\mathrm{Sn}$ and DGT). For the full-cell performance, a commercial lithium-nickel cobalt manganese oxide (NCM622, Tianjin B\&M Science and Technology Co., Ltd) was used as the cathode with a fixed areal capacity of $3.2 \mathrm{~mA} \mathrm{~h} \mathrm{~cm}^{-2}$. The $\mathrm{N} / \mathrm{P}$ ratio, defined by total capacity ratio between anode and cathode, was chosen to be 1.0-1.1. The capacities were calculated according to the electrode mass loading, including the binder and carbon black.

\section{Data availability}

The data supporting the findings of this work are available within the article and its Supplementary Information files. All other relevant data supporting the findings of this study are available from the corresponding author on request.

Received: 22 May 2019; Accepted: 17 December 2019; Published online: 13 March 2020

\section{References}

1. Tarascon, J. M. \& Armand, M. Issues and challenges facing rechargeable lithium batteries. Nature 414, 359-367 (2001).

2. Arico, A. S., Bruce, P., Scrosati, B., Tarascon, J. M. \& Schalkwijk, W. V. Nanostructured materials for advanced energy conversion and storage devices. Nat. Mater. 4, 366-377 (2005).

3. Chiang, Y.-M. Building a better battery. Science 330, 1485-1486 (2010).

4. Simon, P. \& Gogotsi, Y. Materials for electrochemical capacitors. Nat. Mater 7, 845-854 (2008).

5. Zhang, Q. F., Uchaker, E., Candelaria, S. L. \& Cao, G. Z. Nanomaterials for energy conversion and storage. Chem. Soc. Rev. 42, 3127-3171 (2013).

6. Yu, P., Popov, B. N., Ritter, J. A. \& White, R. E. Determination of the lithium ion diffusion coefficient in graphite. J. Electrochem. Soc. 146, 8-14 (1999).

7. Obrovac, M. N. \& Chevrier, V. L. Alloy negative electrodes for Li-ion batteries. Chem. Rev. 114, 11444-11502 (2014).

8. Yoshio, M. et al. Improvement of natural graphite as a lithium-ion battery anode material, from raw flake to carbon-coated sphere. J. Mater. Chem. 14, 1754-1758 (2004)

9. Dreizler, A. M. et al. Investigation of the influence of nanostructured $\mathrm{LiNi}_{0.33} \mathrm{Co}_{0.33} \mathrm{Mn}_{0.33} \mathrm{O}_{2}$ lithium-ion battery electrodes on performance and aging. J. Electrochem. Soc. 165, A273-A282 (2018).

10. Kim, Y. S. et al. Lithium nickel cobalt manganese oxide synthesized using alkali chloride flux: morphology and performance as a cathode material for lithium ion batteries. ACS Appl. Mater. Interfaces 4, 2329-2333 (2012).

11. Kim, J. H. et al. Prospect and reality of Ni-rich cathode for commercialization. Adv. Energy Mater. 8, 1702028 (2018). 
12. Magasinski, A. et al. High-performance lithium-ion anodes using a hierarchical bottom-up approach. Nat. Mater. 9, 353-358 (2010).

13. Yu, Y. et al. Reversible storage of lithium in silver-coated three-dimensional macroporous silicon. Adv. Mater. 22, 2247-2250 (2010).

14. Yu, Y., Gu, L., Zhu, C., Aken, P. A. \& Maier, J. Tin nanoparticles encapsulated in porous multichannel carbon microtubes: preparation by single-nozzle electrospinning and application as anode material for high-performance Libased batteries. J. Am. Chem. Soc. 131, 15984-15985 (2009).

15. Chan, C. K., Zhang, X. F. \& Cui, Y. High capacity Li ion battery anodes using Ge nanowires. Nano Lett. 8, 307-309 (2008).

16. Kim, M. G., Sim, S. \& Cho, J. Novel core-shell Sn-Cu anodes for lithium rechargeable batteries prepared by a redox-transmetalation reaction. $A d v$. Mater. 22, 5154-5158 (2010).

17. $\mathrm{Xu}, \mathrm{Y}$. et al. Uniform nano-Sn/C composite anodes for lithium ion batteries. Nano Lett. 13, 470-474 (2013).

18. Mao, M. L. et al. Pipe-wire $\mathrm{TiO}_{2}$-Sn@carbon nanofibers paper anodes for lithium and sodium ion batteries. Nano Lett. 17, 3830-3836 (2017).

19. Inoue, H. High capacity negative-electrode materials next to carbon; Nexelion. Pap. Presente. Int. Meet. Lithium Batteries Biarritz Fr. June 228, 18-23 (2006).

20. Naille, S., Dedryvère, R., Zitoun, D. \& Lippens, P.-E. Atomic-scale characterization of tin-based intermetallic anodes. J. Power Sources 189, 806-808 (2009).

21. Wang, X. L. et al. Nanospheres of a new intermetallic $\mathrm{FeSn}_{5}$ phase: synthesis, magnetic properties and anode performance in Li-ion batteries. J. Am. Chem. Soc. 133, 11213-11219 (2011).

22. Liu, J., Wen, Y. R., van Aken, P. A., Maier, J. \& Yu, Y. Facile synthesis of highly porous $\mathrm{Ni}-\mathrm{Sn}$ intermetallic microcages with excellent electrochemical performance for lithium and sodium storage. Nano Lett. 14, 6387-6392 (2014).

23. Behdokht, F. et al. Anodes for sodium ion batteries based on tin germanium antimony alloys. ACS Nano. 8, 4415-4429 (2014).

24. Lin, J. et al. Self-assembled $\mathrm{Cu}-\mathrm{Sn}-\mathrm{S}$ nanotubes with high (de)lithiation performance. ACS Nano. 11, 10347-10356 (2017).

25. Xu, Y. L., Peng, B. \& Mulder, F. M. A high-rate and ultrastable sodium ion anode based on a novel $\mathrm{Sn}_{4} \mathrm{P}_{3}$-P@graphene nanocomposite. Adv. Energy Mater. 8, 1701847 (2018).

26. Ji, L. W. et al. Multilayer nanoassembly of Sn-nanopillar arrays sandwiched between graphene layers for high-capacity lithium storage. Energy Environ. Sci. 4, 3611-3616 (2011).

27. Zou, Y. Q. \& Wang, Y. Sn@CNT nanostructures rooted in graphene with high and fast Li-storage capacities. ACS Nano. 5, 8108-8114 (2011).

28. Han, X. G. et al. Atomic-layer-deposition oxide nanoglue for sodium ion batteries. Nano Lett. 14, 139-147 (2014).

29. Zhu, Z. Q. et al. Ultrasmall Sn nanoparticles embedded in nitrogen-doped porous carbon as high-performance anode for lithium-ion batteries. Nano Lett. 14, 153-157 (2014).

30. Liao, J. Y. \& Manthiram, A. A hierarchical tin/carbon composite as an anode for lithium-ion batteries with a long cycle life. Adv. Energy Mater. 4, 1400403 (2014).

31. Qin, J. et al. Graphene networks anchored with Sn@graphene as lithium ion battery anode. ACS Nano. 8, 1728-1738 (2014).

32. Huang, X. K. et al. A hierarchical tin/carbon composite as an anode for lithium-ion batteries with a long cycle life. Angew. Chem. Int. Ed. 54, 1490-1493 (2015).

33. Liu, Y. C., Zhang, N., Jiao, L. F., Tao, Z. L. \& Chen, J. Ultrasmall Sn nanoparticles embedded in carbon as high-performance anode for sodium-ion batteries. Adv. Funct. Mater. 25, 214-220 (2015).

34. Youn, D. H., Heller, A. \& Mullins, C. B. Simple synthesis of nanostructured $\mathrm{Sn} /$ nitrogen-doped carbon composite using nitrilotriacetic acid as lithium ion battery anode. Chem. Mater. 28, 1343-1347 (2016).

35. Zhang, H. W., Huang, X. D., Noonan, O., Zhou, L. \& Yu, C. Z. Tailored yolkshell Sn@C nanoboxes for high-performance lithium storage. Adv. Funct. Mater. 27, 1606023 (2017).

36. Kravchyk, K. et al. Monodisperse and inorganically capped $\mathrm{Sn}$ and $\mathrm{Sn} / \mathrm{SnO}_{2}$ nanocrystals for high-performance Li-ion battery anodes. J. Am. Chem. Soc. 135, 4199-4202 (2013).

37. Hyung, S. I. et al. Phase evolution of tin nanocrystals in lithium ion batteries. ACS Nano. 7, 11103-11111 (2013).

38. Hassoun, J., Panero, S., Simon, P., Taberna, P. L. \& Scrosati, B. High-rate, long-life $\mathrm{Ni}-\mathrm{Sn}$ nanostructured electrodes for lithium-ion batteries. $A d v$. Mater. 19, 1632-1635 (2007)

39. Liu, Y. C., Zhang, N., Jiao, L. F. \& Chen, J. Tin nanodots encapsulated in porous nitrogen-doped carbon nanofibers as a free-standing anode for advanced sodium-ion batteries. Adv. Mater. 27, 6702-6707 (2015).

40. Han, J. W. et al. Caging tin oxide in three-dimensional graphene networks for superior volumetric lithium storage. Nat. Commun. 9, 402 (2018).

41. Li, Y. Z. et al. Growth of conformal graphene cages on micrometre-sized silicon particles as stable battery anodes. Nano Energy 1, 15029 (2016).
42. Mo, R. W., Rooney, D., Sun, K. N. \& Yang, H. Y. 3D nitrogen-doped graphene foam with encapsulated germanium/nitrogen-doped graphene yolk-shell nanoarchitecture for high-performance flexible Li-ion battery. Nat. Commun. 8, 13949 (2017).

43. Gogotsi, Y. \& Simon, P. True performance metrics in electrochemical energy storage. Science 334, 917-918 (2011).

44. Beattie, S. D., Hatchard, T., Bonakdarpour, A., Hewitt, K. C. \& Dahn, J. R. Anomalous, high-voltage irreversible capacity in tin electrodes for lithium batteries. J. Electrochem. Soc. 150, A701-A705 (2003).

45. Chen, Z. et al. High-performance supercapacitors based on intertwined CNT/ $\mathrm{V}_{2} \mathrm{O}_{5}$ nanowire nanocomposites. Adv. Mater. 23, 791-795 (2011).

46. Mo, R. W., Lei, Z. Y., Sun, K. N. \& Rooney, D. Facile synthesis of anatase $\mathrm{TiO}_{2}$ quantum-dot/graphene-nanosheet composites with enhanced electrochemical performance for lithium-ion batteries. Adv. Mater. 26, 2084-2088 (2014).

47. Ellis, L. D., Hatchard, T. D. \& Obrovac, M. N. Reversible insertion of sodium in tin. J. Electrochem. Soc. 159, A1801-A1805 (2012).

48. Wang, B. et al. Folding graphene film yields high areal energy storage in lithium-ion batteries. ACS Nano. 12, 1739-1746 (2018).

49. $\mathrm{Xu}, \mathrm{Y}$. X. et al. Solvated graphene frameworks as high-performance anodes for lithium-ion batteries. Angew. Chem. Int. Ed. 54, 5345-5350 (2015).

50. Son, I. H. et al. Graphene balls for lithium rechargeable batteries with fast charging and high volumetric energy densities. Nat. Commun. 8, 1561 (2017).

51. Moshtev, R. \& Johnson, B. State of the art of commercial Li ion batteries. J. Power Sources 91, 86-91 (2016)

52. Kim, N., Chae, S., Ma, J. Y., Ko, M. \& Cho, J. Fast-charging high-energy lithium-ion batteries via implantation of amorphous silicon nanolayer in edge-plane activated graphite anodes. Nat. Commun. 8, 812 (2017).

53. Ko, M. et al. Scalable synthesis of silicon-nanolayer-embedded graphite for high-energy lithium-ion batteries. Nat. Energy 1, 16113 (2016).

54. Zhu, G. N. et al. Carbon-coated nano-sized $\mathrm{Li}_{4} \mathrm{Ti}_{5} \mathrm{O}_{12}$ nanoporous microsphere as anode material for high-rate lithium-ion batteries. Energy Environ. Sci. 4, 4016-4022 (2011).

55. Johnson, B. A. \& White, R. E. Characterization of commercially available lithium-ion batteries. J. Power Sources 70, 48-54 (1998).

56. Jung, H. G., Kim, J. H., Scrosati, B. \& Sun, Y. K. Micron-sized, carbon-coated $\mathrm{Li}_{4} \mathrm{Ti}_{5} \mathrm{O}_{12}$ as high power anode material for advanced lithium batteries. $J$. Power Sources 196, 7763-7766 (2011).

57. Wang, X. P. et al. High-density monolith of N-doped holey graphene for ultrahigh volumetric capacity of Li-ion batteries. Adv. Energy Mater. 6, 1502100 (2016).

58. Liu, J. Y. et al. High volumetric capacity three-dimensionally sphere-caged secondary battery anodes. Nano Lett. 16, 4501-4507 (2016).

59. Luo, J. M. et al. $\mathrm{Sn}^{4+}$ ion decorated highly conductive $\mathrm{Ti}_{3} \mathrm{C}_{2}$ Mxene: promising lithium-ion anodes with enhanced volumetric capacity and cyclic performance. ACS Nano. 10, 2491-2499 (2016).

60. Liang, J. et al. Bowl-like $\mathrm{SnO}_{2} @$ carbon hollow particles as an advanced anode material for lithium-ion batteries. Angew. Chem. Int. Ed. 53, 12803-12807 (2014).

61. Yin, J. F., Cao, H. Q., Zhou, Z. F., Zhang, J. X. \& Qu, M. Z. SnS @@reduced graphene oxide nanocomposites as anode materials with high capacity for rechargeable lithium ion batteries. J. Mater. Chem. 22, 23963-23970 (2012).

62. $\mathrm{Wu}, \mathrm{H}$. et al. Stable Li-ion battery anodes by in-situ polymerization of conducting hydrogel to conformally coat silicon nanoparticles. Nat. Commun. 4, 1943 (2013).

63. Xia, F. et al. Facile synthesis of free-Standing silicon membranes with threedimensional nanoarchitecture for anodes of lithium ion batteries. Nano Lett. 13, 3340-3346 (2013)

\section{Acknowledgements}

We are grateful to funding support from the UCLA ENN Center for Nanomedicine and Energy Conversion. This work was also financially supported by the National Nature Science Foundation of China (NSFC 51972207) and Science and Technology Commission of Shanghai Municipality (19DZ2271100).

\section{Author contributions}

Y.L. and R.M. conceived the idea. R.M., X.T., F.L., and R.T. carried out material synthesis, characterization and electrochemical characterization. X.W. and C.W. performed the in situ TEM characterization. J.X., D.K., B.X. Z.W., and Y.P. also contributed to the related experiments. R.M., J.L. and Y.L., co-wrote the paper. All the authors discussed the results and commented on the manuscript.

\section{Competing interests}

The authors declare no competing interests. 


\section{Additional information}

Supplementary information is available for this paper at https://doi.org/10.1038/s41467020-14859-z.

Correspondence and requests for materials should be addressed to Y.P. or Y.L.

Peer review information Nature Communications thanks Liang An, Chunnian He and Se-Hee Lee for their contribution to the peer review of this work.

Reprints and permission information is available at http://www.nature.com/reprints

Publisher's note Springer Nature remains neutral with regard to jurisdictional claims in published maps and institutional affiliations. (c) Open Access This article is licensed under a Creative Commons Attribution 4.0 International License, which permits use, sharing, adaptation, distribution and reproduction in any medium or format, as long as you give appropriate credit to the original author(s) and the source, provide a link to the Creative Commons licence, and indicate if changes were made. The images or other third party material in this article are included in the article's Creative Commons licence, unless indicated otherwise in a credit line to the material. If material is not included in the article's Creative Commons licence and your intended use is not permitted by statutory regulation or exceeds the permitted use, you will need to obtain permission directly from the copyright holder. To view a copy of this licence, visit http://creativecommons.org/licenses/by/4.0/.

(C) The Author(s) 2020 